\title{
A review by the chief editors of some of the most popular papers published by PEPS in 2014-2015
}

\author{
Yasufumi Iryu ${ }^{1 *}$, Kiyoshi Kuramoto ${ }^{2}$, Masaki Satoh $^{3}$, Jun Matsumoto ${ }^{4}$, Shoichi Yoshioka ${ }^{5}$, Hodaka Kawahata ${ }^{3}$ and \\ Ryuji Tada ${ }^{6}$
}

\section{Introduction}

Progress in Earth and Planetary Science (PEPS) was founded in late 2013, and the first article was published in March 2014. As of the end of December 2015, PEPS has published 75 articles (including 22 review articles); the total number of online accesses exceeds 140,000 and more than 70,000 papers have been downloaded. Further, PEPS articles have been cited in international journals registered by Web of Science more than 84 times. We feel that these numbers indicate that PEPS continues to make steady progress.

At the start of 2016, we would like to take the opportunity to review some of the outstanding articles published from PEPS in 2014 and 2015. We have chosen papers from amongst the most popular and highly cited downloads, in the hope that these will provide insight into some of the work that has been undertaken recently in earth and planetary sciences around the world and will help to stimulate further study. Many of us feel that other papers should have been included here, and we are sure that many of our readers feel likewise; however, we wished to use an objective criterion for selection, and reader popularity seems to us to be the best choice.

\section{Review}

\section{Space and planetary sciences}

Tsuda T, Shepherd M. Gopalswamy N (2015). Advancing the understanding of the Sun-Earth interaction-the Climate and Weather of the Sun-Earth System (CAWSES) II program. Prog Earth Planet Sci 2:28, doi:10.1186/s40645015-0059-0.

It is important to investigate the interaction between different layers (e.g., magnetosphere-ionosphereatmosphere-ocean) in the study of the earth environment.

\footnotetext{
* Correspondence: iryu@m.tohoku.ac.jp

${ }^{1}$ Institute of Geology and Paleontology, Graduate School of Science, Tohoku

University, Aramaki-aza-aoba 6-3, Aoba-ku, Sendai 980-8578, Japan

Full list of author information is available at the end of the article
}

PEPS has provided a series of review papers describing the latest progress made by the CAWSES-II international research program, and Tsuda et al. (2015) provides a good introduction.

McCrea I, Aikio A, Alfonsi L, Belova E, Buchert S, Clilverd M, Engler N, Gustavsson B, Heinselman C, Kero J, Kosch M, Lamy H, Leyser T, Ogawa Y, Oksavik K, Pellinen-Wannberg A, Pitout F, Rapp M, Stanislawska I, Vierinen J (2015) The science case for the EISCAT_3D radar. Prog Earth Planet Sci 2:21, doi:10.1186/s40645015-0051-8.

The EISCAT_3D radar described in McCrea et al. (2015) will be a new strong tool to investigate both the upper atmosphere and the ionosphere. This paper gives readers useful knowledge of the radar system as well as the physics which the EISCAT_3D radar is designed to investigate.

Taguchi S, Hosokawa K, Ogawa Y (2015) Investigating the particle precipitation of a moving cusp aurora using simultaneous observations from the ground and space. Prog Earth Planet Sci 2:11, doi:10.1186/s40645-0150044-7.

The dayside cusp is the region where the magnetic field lines are open to interplanetary space. Taguchi et al. (2015) investigated the precipitating particle feature in the cusp aurora using both high-sensitivity all-sky imagers on the ground and in situ spacecraft observation. They conclude that the electron precipitating flux in the moving cusp aurora is controlled by a mechanism independent of the ion precipitation, and this is sure to be useful for the further study of auroral phenomena.

\section{Atmospheric and hydrospheric sciences \\ Satoh M, Tomita H, Yashiro H, Miura H, Kodama C, Seiki T, Noda AT, Yamada Y, Goto D, Sawada M, Miyoshi T, Niwa Y, Hara M, Ohno Y, Iga S, Arakawa T, Inoue T, Kubokawa H (2014) The Non-hydrostatic Icosahedral}


Atmospheric Model: description and development. Prog Earth Planet Sci 1:18 doi:10.1186/s40645-014-0018-1.

Satoh et al. (2014) introduced global non-hydrostatic atmospheric models and overviewed the scientific aspects and development of the Non-hydrostatic Icosahedral Atmospheric Model (NICAM). NICAM is known as the first practically used global non-hydrostatic atmospheric model and was recently run with a mesh size of less than a kilometer over the global spherical domain. The paper reviewed both the past decade's work and the ongoing activities of NICAM.

Hajima T, Kawamiya M, Watanabe M, Kato E, Tachiiri K, Sugiyama M, Watanabe S, Okajima H, Ito A (2014) Modeling in Earth system science up to and beyond IPCC AR5. Prog Earth Planet Sci 1:29, doi:10.1186/ s40645-014-0029-y.

Hajima et al. (2014) reviewed recent progress in Earth system models (ESMs), focusing mainly on the latest assessment report of the Intergovernmental Panel on Climate Change. They introduced a number of tasks under discussion for the next phases of the following areas of science: the global nitrogen cycle, ocean acidification, landuse and land-cover change, ESMs of intermediate complexity, climate geoengineering, ocean $\mathrm{CO}_{2}$ uptake, and deposition of bioavailable iron in marine ecosystems.

Vincent RA (2015) The dynamics of the mesosphere and lower thermosphere: a brief review. Prog Earth Planet Sci 2:4 doi:10.1186/s40645-015-0035-8.

Vincent (2015) presented a brief review of the dynamics of the mesosphere-lower thermosphere (MLT), with a particular emphasis on developments in the past decade. The dynamics of the MLT is dominated by waves and their effects. The basic structure of the MLT is determined by momentum deposition by small-scale gravity waves, which drives a summer-to-winter pole circulation at the mesopause. Various aspects of these waves and their effects on the MLT are presented with a particular focus on wintertime sudden stratospheric warmings which temporarily disrupt the circulation pattern and thermal structure of the MLT.

\section{Human geosciences}

Chen C-W, Saito H, Oguchi T (2015) Rainfall intensityduration conditions for mass movements in Taiwan. Prog Earth Planet Sci 2:14, doi:10.1186/s40645-0150049-2.

Chen et al. (2015) analyzed 263 mass movements caused by heavy rainfall events in Taiwan during a 7 -year period from 2006 to 2012. They obtained the rainfall intensityduration relationship to establish a rainfall threshold for mass movements. Significant differences were found between rainfall intensities and thresholds for landslides and debris flows. The results of their analysis will not only contribute to the geomorphic development in humid and active tectonic region such as Taiwan but also contribute to disaster prevention by giving good fundamental guidance as to when to issue high risk alerts for the occurrence of landslides and/or debris flow.

\section{Solid earth sciences}

Mysen B (2014) Water-melt interaction in hydrous magmatic systems at high temperature and pressure. Prog Earth Planet Sci 1:4, doi: doi:10.1186/2197-4284-1-4.

Mysen (2014) reviewed experimental data on the structure and properties of melts and fluids relevant to watermelt interaction in hydrous magmatic systems in the Earth's interior. Complex relationships between water solubility in melts and their bulk composition explain why water solubility in felsic magmas is significantly greater than water solubility in basalt melts. Silicate solubility in aqueous fluid is also significantly dependent on composition with metal oxide/( $\mathrm{Al}+\mathrm{Si})$ and electron properties of the metal cations the dominant variables. He also addressed the important issue of how the properties of hydrous melts and aqueous solutions are governed by how the silicate speciation varies with bulk composition, silicate composition, temperature, and pressure.

Ujiie K, Kimura G (2014) Earthquake faulting in subduction zones: insights from fault rocks in accretionary prisms. Prog Earth Planet Sci, 1:7 doi:10.1186/21974284-1-7.

Ujiie and Kimura (2014) introduced key advances that have been made over the last decade in the study of fault rocks and in laboratory experiments using fault zone materials, with a particular focus on the Nankai Trough subduction zone and its on-land analog, the Shimanto accretionary complex in Japan. New insights into earthquake faulting in subduction zones were discussed in the following areas: the occurrence of seismic slip along velocity-strengthening materials both at shallow and deep depths; dynamic weakening of faults by melt lubrication and fluidization and possible factors controlling coseismic deformation mechanisms; fluid-rock interactions and mineralogical and geochemical changes during earthquakes; and geological and experimental aspects of slow earthquakes.

Nishimura T (2014) Short-term slow slip events along the Ryukyu Trench, southwestern Japan, observed by continuous GNSS. Prog Earth Planet Sci 1:21, doi:10.1186/ s40645-014-0022-5.

Nishimura (2014) used continuous global navigation satellite system (GNSS) data to systematically investigate short-term slow slip events (SSEs) along the Ryukyu Trench in southwestern Japan. A total of 130 probable and 93 possible short-term SSEs in the moment magnitude range of 5.6 to 6.8 were identified from January 1997 to November 2013 by GNSS time series offset monitoring and elastic dislocation modeling with a 
rectangular fault located on the subducting Philippine Sea Plate. The detected short-term SSEs were found to have a variety of characteristic recurrence intervals, magnitudes, durations, and coincidental seismic activities. Based on this study, he suggested that the distribution of short-term SSEs, as well as that of large earthquakes, was affected by the topography of the subducting plate.

\section{Biogeosciences}

Nakamura K, Takai K (2014) Theoretical constraints of physical and chemical properties of hydrothermal fluids on variations in chemolithotrophic microbial communities in seafloor hydrothermal systems. Prog Earth Planet Sci 1:5, doi:10.1186/2197-4284-1-5.

Chemosynthetic ecosystems at deep-sea hydrothermal vents have received much attention as plausible analogs both to the early ecosystems of the Earth and also to extraterrestrial ecosystems. Nakamura and Takai (2014) calculated the metabolic energy potentially available for productivity by chemolithotrophic microorganisms and compared the results with observed variability. $\mathrm{H}_{2}$ concentrations impact organisms with aerobic and anaerobic hydrogenotrophic metabolisms the most while $\mathrm{CH}_{4}$ concentration also has a considerable impact on organisms. These results will provide useful guidance for future research addressing the origin and early evolution of life on and outside the Earth.

Ohkouchi N, Ogawa NO, Chikaraishi Y, Tanaka H, Wada E (2015) Biochemical and physiological bases for the use of carbon and nitrogen isotopes in environmental and ecological studies. Prog Earth Planet Sci 2:1 doi:10.1186/s40645-015-0032-y.

The second biogeosciences topic covers the use of carbon and nitrogen isotopes in environmental and ecological studies. Ohkouchi et al. (2015) reviewed the latest results from this research field together with the underlying theoretical background, and discussed how biochemical processes commonly observed in the biosphere, including the decarboxylation and deamination of amino acids, are the key factors in this isotopic approach. Energy flow in ecosystems is essential for understanding the surface environment of this planet, and compound-specific isotopic analysis is effective for this kind of the study. Of particular interest, chlorophylls provide information about the particular processes of various photoautotrophs, and amino acids provide a precise measure of the trophic positions of heterotrophs. Understanding the isotopic distributions of carbon and nitrogen in a single organism as well as in the whole biosphere is sure to receive much more attention in the future.

\section{Interdisciplinary research}

Gallagher SJ, Kitamura A, Iryu Y, Itaki T, Koizumi I, Hoiles PW (2015) The Pliocene to recent history of the Kuroshio and Tsushima Currents: a multi-proxy approach. Prog Earth Planet Sci 2:17 doi:10.1186/s40645015-0045-6.

In SPEPS "Land-Ocean Linkages under the Influence of the Asian Monsoon," Gallagher et al. (2015) reviewed the history of changes in intensities and courses of the Kuroshio and Tsushima Currents since the Pliocene. The Kuroshio Current is a major western boundary current in the North Pacific and the Tsushima Current branches from the Kuroshio and flows into the Japan Sea. Both currents exert a significant impact on climate in East Asia including Japan. Evolution of these currents during the time of northern hemisphere glaciation is reviewed based on a multi-proxy approach. The result provides useful implication on their behavior in response to future global warming.

\section{Acknowledgements}

We would like to take this opportunity to thank all of the PEPS editors and reviewers for their diligence in making balanced assessments of and providing useful comments on manuscripts submitted to PEPS. Finally, we must thank the editorial assistants Ms. Tomoyo Asada and Ms. Mayumi

Okada for all of the hard work that they put in behind the scenes.

\section{About PEPS}

Progress in Earth and Planetary Science (PEPS) is an international open-access e-journal published by the Japan Geoscience Union (JpGU) in partnership with Springer. PEPS aims to publish high-quality original research and review articles in a wide range of research fields: space and planetary sciences, atmospheric and hydrospheric sciences, human geosciences, solid earth sciences, and biogeosciences. PEPS is an open-access e-journal, and so anyone who is interested may read and download any of its articles without any expense wherever there is access to the Internet.

Recently, the "Open Science" concept has been discussed, supported, and promoted by the governments of many countries. The open-access publication style is consistent with this concept and hopefully will help to prevent the monopoly of science by a small number of publishers. "Open Science" may also change the relationship between science and citizens because ordinary people can access the latest scientific research results much more easily than was possible in the past. In view of all of this, we, the PEPS General Chief Editor and the Science Section Chief Editors, think it our important mission to continue to raise PEPS to be a leading journal in the field of earth and planetary science.

\section{Author details}

${ }^{1}$ Institute of Geology and Paleontology, Graduate School of Science, Tohoku University, Aramaki-aza-aoba 6-3, Aoba-ku, Sendai 980-8578, Japan.

${ }^{2}$ Department of Cosmosciences, Graduate School of Science, Hokkaido University, Kita 10, Nishi 8, Kita-ku, Sapporo, Hokkaido 060-0810, Japan. ${ }^{3}$ Atmosphere and Ocean Research Institute, The University of Tokyo, 5-1-5 Kashiwanoha, Kashiwa-shi, Chiba 277-8564, Japan. ${ }^{4}$ Department of Geography, Graduate School of Urban Environmental Sciences, Tokyo Metropolitan University, 6-6 Asahigaoka, Hino-shi, Tokyo 191-0065, Japan. ${ }^{5}$ Research Center for Urban Safety and Security, Kobe University, Rokkodai-cho 1-1, Nada-ku Kobe 657-8501, Japan. ${ }^{6}$ Department of Earth and Planetary Science, Graduate School of Science, The University of Tokyo, 7-3-1 Hongo, Bunkyo-ku, Tokyo 113-0033, Japan.

Received: 10 December 2015 Accepted: 5 January 2016 Published online: 28 January 2016

\section{References}

Chen C-W, Saito H, Oguchi T (2015) Rainfall intensity-duration conditions for mass movements in Taiwan. Prog Earth Planet Sci 2:14. doi:10.1186/s40645015-0049-2 
Gallagher SJ, Kitamura A, Iryu Y, Itaki T, Koizumi I, Hoiles PW (2015) The Pliocene to recent history of the Kuroshio and Tsushima Currents: a multi-proxy approach. Prog Earth Planet Sci 2:17. doi:10.1186/s40645-015-0045-6

Hajima T, Kawamiya M, Watanabe M, Kato E, Tachiiri K, Sugiyama M, Watanabe S, Okajima H, Ito A (2014) Modeling in Earth system science up to and beyond IPCC AR5. Prog Earth Planet Sci 1:29. doi:10.1186/s40645-014-0029-y

McCrea I, Aikio A, Alfonsi L, Belova E, Buchert S, Clilverd M et al (2015) The science case for the EISCAT_3D radar. Prog Earth Planet Sci 2:21. doi:10.1186/ s40645-015-0051-8

Mysen B (2014) Water-melt interaction in hydrous magmatic systems at high temperature and pressure. Prog Earth Planet Sci 1:4. doi:10.1186/ 2197-4284-1-4

Nakamura K, Takai K (2014) Theoretical constraints of physical and chemical properties of hydrothermal fluids on variations in chemolithotrophic microbial communities in seafloor hydrothermal systems. Prog Earth Planet Sci 1:5, doi:10.1186/2197-4284-1-5

Nishimura T (2014) Short-term slow slip events along the Ryukyu Trench, southwestern Japan, observed by continuous GNSS. Prog Earth Planet Sci 1: 21. doi:10.1186/s40645-014-0022-5

Ohkouchi N, Ogawa NO, Chikaraishi Y, Tanaka H, Wada E (2015) Biochemical and physiological bases for the use of carbon and nitrogen isotopes in environmental and ecological studies. Prog Earth Planet Sci 2:1. doi:10.1186/ s40645-015-0032-y

Satoh M, Tomita H, Yashiro H, Miura H, Kodama C, Seiki T, Noda AT, Yamada Y, Goto D, Sawada M, Miyoshi T, Niwa Y, Hara M, Ohno Y, Iga S, Arakawa T, Inoue T, Kubokawa H (2014) The Non-hydrostatic Icosahedral Atmospheric Model: Description and development. Prog Earth Planet Sci 1:18. doi:10.1186/ s40645-014-0018-1

Taguchi S, Hosokawa K, Ogawa Y (2015) Investigating the particle precipitation of a moving cusp aurora using simultaneous observations from the ground and space. Prog Earth Planet Sci 2:11. doi:10.1186/s40645-015-0044-7

Tsuda T, Shepherd M, Gopalswamy N (2015) Advancing the understanding of the sun-earth interaction - the Climate and Weather of the Sun-Earth System (CAWSES) II program. Prog Earth Planet Sci 2:28. doi:10.1186/s40645-0150059-0

Ujiie K, Kimura G (2014) Earthquake faulting in subduction zones: insights from fault rocks in accretionary prisms. Prog Earth Planet Sci 1:7. doi:10.1186/21974284-1-7

Vincent RA (2015) The dynamics of the mesosphere and lower thermosphere: a brief review. Prog Earth Planet Sci 2:4. doi:10.1186/s40645-015-0035-8

\section{Submit your manuscript to a SpringerOpen ${ }^{\circ}$ journal and benefit from:}

- Convenient online submission

- Rigorous peer review

Immediate publication on acceptance

- Open access: articles freely available online

- High visibility within the field

- Retaining the copyright to your article 